\title{
TEMPERATURAS CARDINAIS PARAA GERMINAÇÃO DE SEMENTES DE Erythrina variegata L. ${ }^{1}$
}

\author{
MIELE TALLON MATHEUS ${ }^{2}$, JOSÉ CARLOS LOPES ${ }^{3}$
}

\begin{abstract}
RESUMO - Objetivou-se com este trabalho determinar as temperaturas cardinais para a germinação das sementes de Erythrina variegata L. Os experimentos foram conduzidos no Laboratório de Análise de Sementes do CCA-UFES, em Alegre-ES. A semeadura foi feita em caixas "gerbox", com areia esterilizada como substrato. Em seguida, as sementes foram incubadas nas temperaturas constantes de $12^{\circ} \mathrm{C}, 14^{\circ} \mathrm{C}, 16^{\circ} \mathrm{C}, 18^{\circ} \mathrm{C}, 20^{\circ} \mathrm{C}, 22^{\circ} \mathrm{C}, 24^{\circ} \mathrm{C}, 26^{\circ} \mathrm{C}, 28^{\circ} \mathrm{C}, 30^{\circ} \mathrm{C}, 32^{\circ} \mathrm{C}, 34^{\circ} \mathrm{C}, 36^{\circ} \mathrm{C}, 38^{\circ} \mathrm{C}$ e $40^{\circ} \mathrm{C}$, com fotoperíodo de 8 horas. O delineamento experimental foi o inteiramente casualizado com quatro repetições de 25 sementes. E. variegata apresentou ampla faixa de tolerância à temperatura, observando-se germinação entre $14^{\circ} \mathrm{C}$ e $38^{\circ} \mathrm{C}$. A faixa de temperatura entre $22^{\circ} \mathrm{C}$ e $36^{\circ} \mathrm{C}$ mostrouse favorável à germinação, com porcentagens acima de $67 \%$. A faixa ótima de temperatura para a germinação das sementes de E. variegata, com base na velocidade e no tempo médio de germinação, esta situada entre $32^{\circ} \mathrm{C}$ e $34^{\circ} \mathrm{C}$ e, com base na porcentagem de germinação, a temperatura ótima é de $34^{\circ} \mathrm{C}$.
\end{abstract}

Termos para indexação: Espécies tropicais, estresse térmico, propagação de plantas.

\section{CARDINAL TEMPERATURES FOR THE GERMINATION OF Erythrina variegata L. SEEDS}

\begin{abstract}
The objective of this study was to determine the optimum germination temperature for seeds of the Erythrina variegata L. The experiments were carried out at the Seed Analysis Laboratory at CCA-UFES (Laboratório de Análise de Sementes of CCA-UFES) in Alegre-ES. The seeds were placed in plastic seed germination containers (gerbox), with sterilized sand as the substrate. Random samples of 25 seeds each were incubated separately at constant temperature of $12^{\circ} \mathrm{C}, 14^{\circ} \mathrm{C}, 16^{\circ} \mathrm{C}, 18^{\circ} \mathrm{C}$, $20^{\circ} \mathrm{C}, 22^{\circ} \mathrm{C}, 24^{\circ} \mathrm{C}, 26^{\circ} \mathrm{C}, 28^{\circ} \mathrm{C}, 30^{\circ} \mathrm{C}, 32^{\circ} \mathrm{C}, 34^{\circ} \mathrm{C}, 36^{\circ} \mathrm{C}, 38^{\circ} \mathrm{C}$ and $40^{\circ} \mathrm{C}$, with 8 -hour photoperiod. This procedure was repeated four times to obtain a meaningful result. It was found that $E$. variegata seeds have a broad range of temperature tolerance with seed germination observed between $14^{\circ} \mathrm{C}$ and $38^{\circ} \mathrm{C}$. Temperatures between $22^{\circ} \mathrm{C}$ and $36^{\circ} \mathrm{C}$ seemed most favorable with germination in excess of $67 \%$. Temperatures between $32^{\circ} \mathrm{C}$ and $34^{\circ} \mathrm{C}$ produced the optimum average rate and time for germination. The highest percentage of E. variegata seed germination was found to be at the temperature of $34^{\circ} \mathrm{C}$.
\end{abstract}

Index terms: Tropical species, thermal stress, plant propagation.

${ }^{1}$ Submetido em 29/08/2008. Aceito para publicação em: 29/03/2009. Parte da Dissertação de Mestrado do primeiro autor, bolsista CAPES no Programa de Pós-Graduação em Produção Vegetal do Centro de Ciências Agrárias da Universidade Federal do Espírito Santo (CCA-UFES).

${ }^{2}$ Eng. Florestal, MSc, Departamento de Jardim Botânico, Fundação Zoo-
Botânica de Belo Horizonte (JB/FZB-BH), Av. Otacílio Negrão de Lima, 8.000 - Pampulha, CEP 31365-450, Belo Horizonte-MG, miele@pbh.gov.br

${ }^{3}$ Eng. Agr., Dr., Prof. Associado, Departamento de Produção Vegetal, CCA-UFES - Campus de Alegre, Cx. Postal 16, CEP 29500-000, AlegreES, jclopes@cca.ufes.br 


\section{INTRODUÇÃO}

Eritrina indiana, Erythrina variegata L.,éumaFabaceae, nativa nas regiões costeiras da Índia e Malásia, empregada em muitos países tropicais para a produção de madeira leve e para polpa celulósica (Lorenzi et al., 2003). É uma espécie arbórea, citada como decídua por diversos autores, como Hegde e Dalla Rosa (1994), Lorenzi et al. (2003) e Whistler e Elevitch (2006). Possui rápido crescimento, atingindo alturas de $15 \mathrm{~m}$ a $20 \mathrm{~m}$, com tronco retilíneo de $50 \mathrm{~cm}$ a $60 \mathrm{~cm}$ de diâmetro, folhas trifoliadas, alternadas, fruto tipo legume deiscente, contendo de 5 a 10 sementes. A árvore é muito utilizada como forrageira, quebra-ventos, cerca viva, como caramanchão para espécies trepadeiras como Piper nigrum (pimenta-do-reino), Vanilla planifolia (baunilha), Dioscorea spp. (inhame ou cará), entre outras; além de ser usada como árvore de sombra entre plantas de café e cacau. Quando em florescimento, pode ser aproveitada para uso paisagístico (Hegde e Dalla Rosa, 1994; Kass, 1994; Lorenzi et al., 2003; Whistler e Elevitch, 2006). Devido à sua capacidade de fixar nitrogênio, é uma espécie capaz de auxiliar na recuperação da fertilidade em solos degradados e ociosos (Whistler e Elevitch, 2006), podendo ser própria para programas de revegetação nessas áreas, em solos com baixa fertilidade e matas ciliares.

As sementes constituem a via de propagação mais empregada na instalação de plantios e, a busca de conhecimentos sobre as condições ótimas para os testes de germinação das sementes, principalmente dando ênfase aos efeitos da temperatura e do substrato, desempenha papel fundamental dentro da pesquisa científica e fornece informações valiosas sobre a propagação e a fisiologia das espécies (Varela et al., 2005).

Hegde (1993) afirma que a propagação de E. variegata é feita facilmente tanto por sementes quanto por meio vegetativo. No entanto, a propagação vegetativa é mais comum quando se utiliza as plantas para cercas vivas, quebra-ventos e para o estabelecimento em áreas com presença de gado, os quais podem comer os brotos das plantas jovens (Wilkinson e Elevitch, 2004). Por outro lado, as sementes geralmente são utilizadas quando se visa o uso da planta como caramanchão para outras culturas, para formação de árvores com maior quantidade de espinhos, ou para a produção de árvores de sombra (Kass, 1994; Wilkinson e Elevitch, 2004).

Para que ocorra a germinação da semente, cada espécie exige condições específicas. A germinação é um processo complexo, que envolve uma sequência de eventos fisiológicos, controlada por diversos fatores, compreendendo diversas fases, as quais são individualmente afetadas pela temperatura. A temperatura age na germinação de três formas, determinando a capacidade e a porcentagem de germinação das sementes, eliminando as dormências primárias e secundárias ou induzindo a dormência secundária (Bewley e Black, 1994).

Cada espécie possui um espectro de temperaturas em que a germinação irá ocorrer (Crocker e Barton, 1957; Bradbeer, 1988; Borges e Rena, 1993; Carvalho e Nakagawa, 2000), embora a faixa de $20^{\circ} \mathrm{C}$ a $30^{\circ} \mathrm{C}$ mostre-se adequada para a germinação de grande número de espécies subtropicais e tropicais (Borges e Rena, 1993). A temperatura ótima propicia a máxima porcentagem de germinação no menor tempo, enquanto sob temperaturas máximas e mínimas a minoria das sementes germina (Bewley e Black, 1994). Sob temperatura baixa, a embebição pode ocorrer, mas poderá não ser seguida pelo crescimento do embrião, ou ainda danos promovidos ao embrião ou às plântulas pela baixa temperatura poderão impedir a conclusão da germinação. Similarmente, altas temperaturas podem permitir a embebição, mas não permitem o crescimento do embrião ou o estabelecimento da plântula (Bradbeer, 1988).

Sabe-se que o processo de germinação envolve uma série de atividades metabólicas, durante as quais ocorre uma sequência programada de reações químicas, cada uma dessas apresentando exigências próprias quanto à temperatura, principalmente porque dependem da atividade de sistemas enzimáticos específicos (Marcos Filho, 2005).

As variações da temperatura também afetam a velocidade, a porcentagem e a uniformidade de germinação, conforme verificado em sementes de Muntingia calabura L. (Lopes et al., 2002); Miconia cinnamomifolia (Dc.) Naud. (Lopes e Soares, 2003); Croton floribundus Spreng. (Abdo e Paula, 2006). Em função de sua relação com esses parâmetros, há necessidade de serem determinadas temperaturas em que a eficiência do processo é total, bem como os extremos (máximo e mínimo) tolerados pelas sementes (Marcos Filho, 2005). Os limites extremos, incluindo a temperatura considerada ótima, representam as temperaturas cardinais para a germinação (Labouriau, 1983; Popinigis, 1985; Mayer e Poljakoff Mayber, 1989; Marcos Filho, 2005).

As temperaturas cardinais para a germinação de Erythrina variegata L. são desconhecidas, contudo, tornam-se informações essenciais para a propagação da espécie e para a avaliação da qualidade de suas sementes. Dessa forma, objetivou-se com este trabalho identificar as 
temperaturas mínima, máxima e ótima para a germinação de sementes de E. variegata.

\section{MATERIAL E MÉTODOS}

As sementes de Erythrina variegata L. utilizadas no presente trabalho foram coletadas de duas matrizes existentes na Área Experimental do Centro de Ciências Agrárias da Universidade Federal do Espírito Santo, UFES, Alegre-ES, $20^{\circ} 45^{\prime} \mathrm{S}$ e $41^{\circ} 28^{\prime} \mathrm{W}$ e altitude de $150 \mathrm{~m}$. Logo após a coleta, as sementes foram extraídas manualmente dos frutos e os experimentos foram conduzidos no Laboratório de Análise de Sementes do CCA-UFES. A semeadura foi feita em caixas acrílicas do tipo "gerbox", utilizando-se como substrato areia esterilizada, umedecida com água destilada até atingir $60 \%$ da capacidade de retenção de água, calculado de acordo com Brasil (1992). Em seguida, as sementes foram incubadas em câmara tipo BOD nas temperaturas constantes de $12^{\circ} \mathrm{C}, 14^{\circ} \mathrm{C}, 16^{\circ} \mathrm{C}, 18^{\circ} \mathrm{C}, 20^{\circ} \mathrm{C}$, $22^{\circ} \mathrm{C}, 24^{\circ} \mathrm{C}, 26^{\circ} \mathrm{C}, 28^{\circ} \mathrm{C}, 30^{\circ} \mathrm{C}, 32^{\circ} \mathrm{C}, 34^{\circ} \mathrm{C}, 36^{\circ} \mathrm{C}, 38^{\circ} \mathrm{C}$ e $40^{\circ} \mathrm{C}$, com fotoperíodo de 8 horas. O delineamento experimental utilizado foi o inteiramente casualizado e para cada temperatura foram utilizadas quatro repetições de 25 sementes. Foi computado diariamente o número de sementes germinadas até a estabilização do estande.

A partir do número de sementes germinadas foi calculada a porcentagem de germinação; o tempo médio de germinação - $\mathrm{t}_{\mathrm{m}}$ (Labouriau, 1983); a velocidade média de germinação - $\bar{v}$ (Labouriau e Valadares, 1976; Labouriau, 1978; Labouriau, 1983); a frequência relativa de germinação - FR (Labouriau e Valadares, 1976; Labouriau, 1978; Santana e Ranal, 2004) e o índice de sincronização de germinação ou incerteza - E (Labouriau e Valadares, 1976; Santana e Ranal, 2004).

A análise estatística foi efetuada através de análise de variância, por meio do teste $\mathrm{F}$ e seguida pela comparação das médias dos tratamentos por meio do teste de agrupamento de Scott-Knott, a $5 \%$ de probabilidade e pela análise de regressão em nível de $5 \%$ de significância. O teste de Cochran evidenciou homocedasticidade das variâncias dos parâmetros em estudo, não havendo, portanto, necessidade de transformação dos dados.

\section{RESULTADOS E DISCUSSÃO}

As sementes germinaram na faixa de temperatura entre $14^{\circ} \mathrm{C}$ e $38^{\circ} \mathrm{C}$, não ocorrendo germinação a $12^{\circ} \mathrm{C}$ e a $40^{\circ} \mathrm{C}$ (Tabela 1). Foi possível observar sinais de deterioração nas sementes que permaneceram sob a temperatura de $40^{\circ} \mathrm{C}$. Entretanto, aquelas que estavam a $12^{\circ} \mathrm{C}$ não apresentaram deterioração até o término da condução do teste. Desse modo, torna-se possível determinar os limites extremos de temperatura para a germinação de sementes de Erythrina variegata $\mathrm{L}$., evidenciando ser $14^{\circ} \mathrm{C}$ a temperatura mínima e, $38^{\circ} \mathrm{C}$, a máxima. Baixas temperaturas, além de determinar redução na porcentagem de germinação, reduzem o processo, devido à redução das atividades enzimáticas no metabolismo da semente. Por outro lado, temperaturas mais elevadas determinam maior velocidade do processo de absorção de água, aceleram as atividades enzimáticas e o processo germinativo (Mayer e Poljakoff Mayber, 1989; Bewley e Black, 1994; Carvalho e Nakagawa, 2000).

Os limites observados no presente estudo demonstram que E. variegata possui um amplo espectro de tolerância à temperatura, podendo ser considerada uma espécie euritérmica, conforme definição apresentada por Perez et al. (1998) para sementes de Peltophorum dubium (Spreng) Taubert. Comportamento similar foi verificado em sementes de Leucaena leucocephala (Lam.) de Wit. por Cavalcante e Perez (1995), que sugerem que essa ampla faixa seja uma característica adaptativa que permite germinação em diferentes ambientes de temperatura.

Extremos semelhantes foram observados por Perez et al. (1998) em sementes de Peltophorum dubium, com limite mínimo de temperatura para germinação entre $9^{\circ} \mathrm{C}$ e $12^{\circ} \mathrm{C}$ e máximo entre $36^{\circ} \mathrm{C}$ e $39^{\circ} \mathrm{C}$.

De acordo com Perez et al. (1998), espécies tropicais geralmente possuem um limite máximo acima de $35^{\circ} \mathrm{C}$, sendo sensíveis às baixas temperaturas, com limite mínimo acima de $5^{\circ} \mathrm{C}$. Dessa forma, E. variegata se caracteriza como uma espécie tropical, o que pode ser confirmado pela sua distribuição geográfica natural nas vegetações costeiras da Índia e Malásia e pela boa adaptação quando introduzida em localidades como o Brasil, a Costa Rica e o Havaí (Faria et al., 1998; Matos et al., 2005; Whistler e Elevitch, 2006).

Verifica-se que a curva de velocidade média de germinação se ajustou ao modelo linear $(P<0,05)$, sendo, portanto, linearmente dependente da temperatura, acima e abaixo da região ótima (Figura 1). Modelos lineares para essa característica também foram verificados em sementes de Dolichos biflorus L. (Labouriau e Pacheco, 1979); Leucaena leucocephala (Cavalcante e Perez, 1995); Peltophorum dubium (Perez et al., 1998) e Senna macranthera (Collad.) Irwin et Barn. (Cassaro Silva, 2001). A interceptação da regressão obtida para a região infraótima localiza a temperatura mínima em $8,86^{\circ} \mathrm{C}$. Por outro 
lado, a interceptação da supra ótima estima um máximo de $41,40^{\circ} \mathrm{C}$. Além disso, as duas retas se interceptam em $33,66^{\circ} \mathrm{C}$, o que se aproxima da temperatura ótima encontrada experimentalmente $\left(34^{\circ} \mathrm{C}\right)$.

TABELA 1. Germinação (\%), tempo médio de germinação (dias) e índice de sincronização de germinação ou incerteza (bits) de Erythrina variegata L. após incubação isotérmica das sementes em diferentes temperaturas $\left({ }^{\circ} \mathrm{C}\right)$.

\begin{tabular}{cccc}
\hline Temperatura & Germinação & Tempo Médio $\left(\mathrm{t}_{\mathrm{m}}\right)$ & Índice de Incerteza (E) \\
\hline 12 & $0 \mathrm{~g}$ & $0,0 \mathrm{f}$ & $0,000 \mathrm{~d}$ \\
14 & $12 \mathrm{f}$ & $21,0 \mathrm{e}$ & $0,500 \mathrm{a}$ \\
16 & $12 \mathrm{f}$ & $21,0 \mathrm{e}$ & $0,500 \mathrm{a}$ \\
18 & $29 \mathrm{e}$ & $19,8 \mathrm{~d}$ & $0,453 \mathrm{a}$ \\
20 & $44 \mathrm{~d}$ & $20,2 \mathrm{~d}$ & $0,944 \mathrm{a}$ \\
22 & $67 \mathrm{c}$ & $10,1 \mathrm{c}$ & $2,118 \mathrm{c}$ \\
24 & $71 \mathrm{c}$ & $9,6 \mathrm{c}$ & $2,294 \mathrm{c}$ \\
26 & $76 \mathrm{c}$ & $7,4 \mathrm{a}$ & $1,500 \mathrm{~b}$ \\
28 & $70 \mathrm{c}$ & $8,4 \mathrm{~b}$ & $2,186 \mathrm{c}$ \\
30 & $84 \mathrm{~b}$ & $8,3 \mathrm{~b}$ & $1,888 \mathrm{~b}$ \\
32 & $83 \mathrm{~b}$ & $6,7 \mathrm{a}$ & $2,179 \mathrm{c}$ \\
34 & $91 \mathrm{a}$ & $7,3 \mathrm{a}$ & $2,099 \mathrm{c}$ \\
36 & $75 \mathrm{c}$ & $9,8 \mathrm{c}$ & $1,659 \mathrm{~b}$ \\
38 & $11 \mathrm{f}$ & $8,5 \mathrm{~b}$ & $0,500 \mathrm{a}$ \\
40 & $0 \mathrm{~g}$ & $0,0 \mathrm{f}$ & $0,000 \mathrm{~d}$ \\
\hline $\mathrm{CV}(\%)$ & 10,97 & 9,43 & 30,98 \\
\hline
\end{tabular}

Médias seguidas de uma mesma letra, nas colunas, não diferem entre si pelo teste de agrupamento de Scott-Knott, a 5\% de probabilidade.

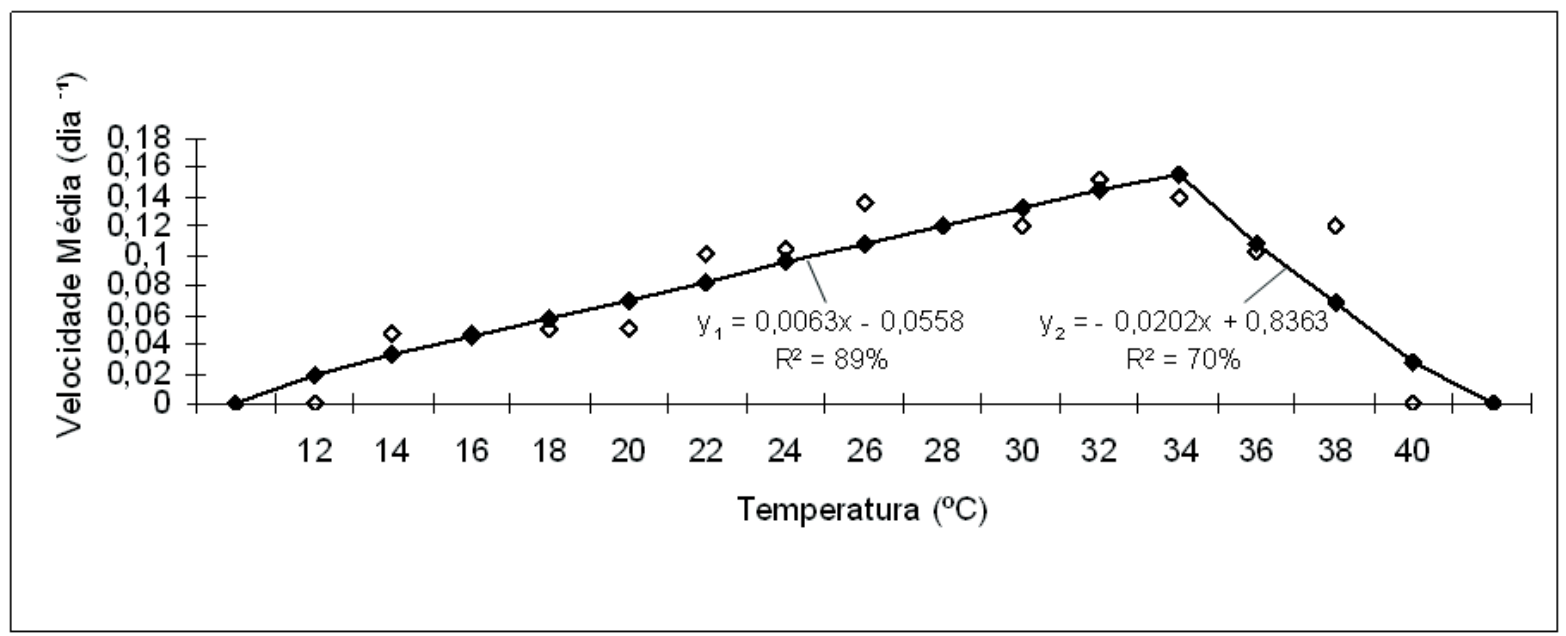

FIGURA 1. Efeitos da temperatura sobre a velocidade média de germinação de sementes de Erythrina variegata L., onde pontos vazios representam a média observada em cada temperatura avaliada e pontos cheios representam as médias estimadas para cada temperatura por meio das equações de regressão $Y_{1}$ (região infra-ótima) e $Y_{2}$ (região supra-ótima). 
A faixa de temperatura entre $22^{\circ} \mathrm{C}$ e $36^{\circ} \mathrm{C}$ mostrou-se favorável à germinação das sementes de $E$. variegata, com porcentagens acima de $67 \%$. Nesse intervalo, $32^{\circ} \mathrm{C}$ e $34^{\circ} \mathrm{C}$ foram as temperaturas que evidenciaram maior velocidade $\mathrm{e}$ menor tempo médio de germinação (Tabela 1). No entanto, essas duas temperaturas diferiram significativamente com relação à porcentagem de germinação, evidenciando maior valor para $34^{\circ} \mathrm{C}$. Isso faz com que a faixa ótima de temperatura para a germinação de sementes de $E$. variegata, com base na velocidade e no tempo médio de germinação, seja entre $32^{\circ} \mathrm{C}$ e $34^{\circ} \mathrm{C}$ e, com base na porcentagem de germinação, seja a temperatura de $34^{\circ} \mathrm{C}$.

Na Figura 2 são apresentadas as curvas de distribuição de frequência da germinação de sementes de E. variegata ao longo do tempo de estudo em cada temperatura, exceto $12^{\circ} \mathrm{C} \mathrm{e} 40^{\circ} \mathrm{C}$, em que a germinação foi nula. Todas as curvas obtidas são leptocúrticas (coeficientes momento de curtose maior que três, ou seja, curvas de freqüência mais afiladas
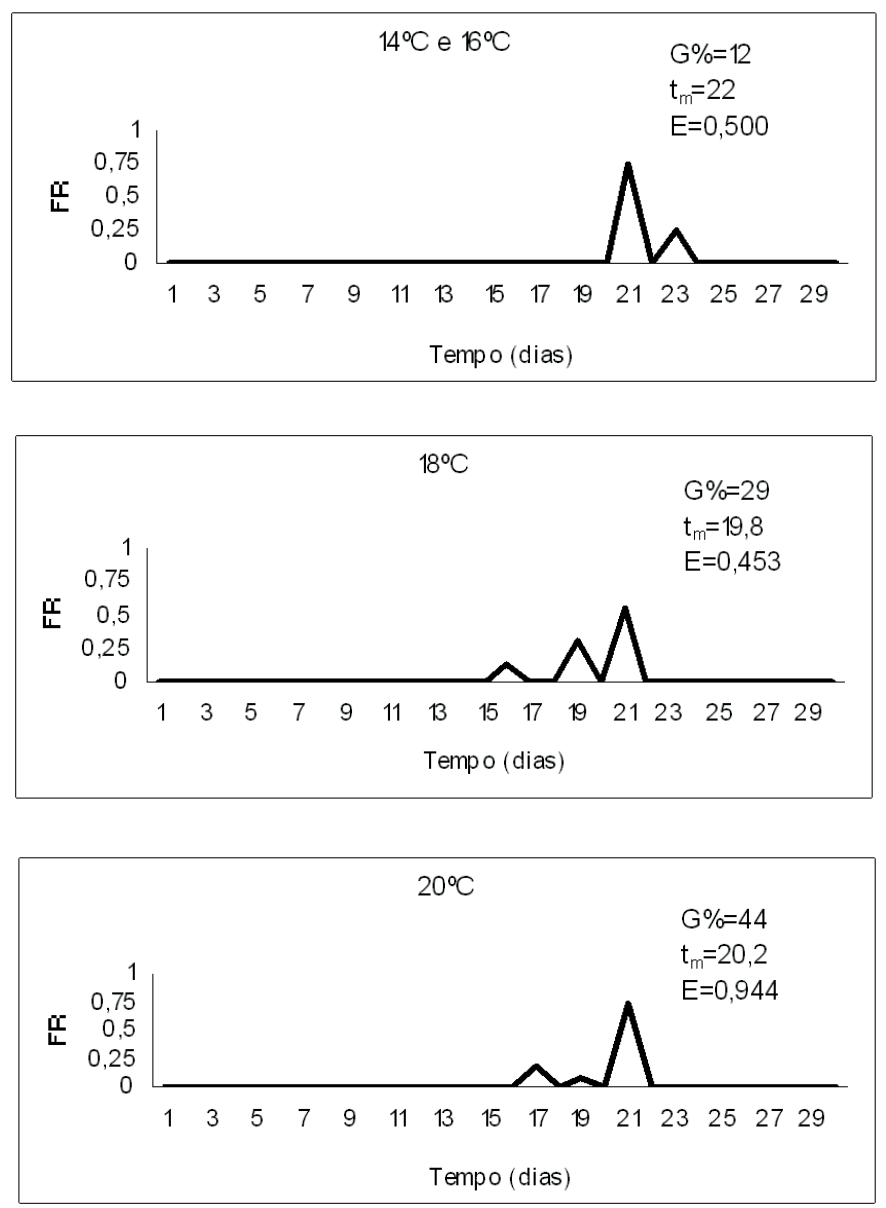

em relação à curva normal). Em geral, observou-se comportamento polimodal nas distribuições isotermas, com mais de um pico de germinação durante o período avaliado, o que demonstra a heterogeneidade fisiológica das sementes de E. variegata. Tal afirmação pode ser reforçada pelo alto índice de incerteza encontrado nas isotermas, mesmo onde a germinação foi relativamente alta, como de $22^{\circ} \mathrm{C}$ à $36^{\circ} \mathrm{C}$. Godoi e Takaki (2005), trabalhando com sementes de Cecropia glaziovi também verificaram que os polígonos de freqüência relativa da germinação apresentaram germinação espalhada no tempo, mesmo na temperatura considerada ótima para a espécie $\left(30^{\circ} \mathrm{C}\right)$, ocorrendo baixa sincronização na germinação. Essa irregularidade na germinação é positivamente relatada por Larcher (2000), pois, quando em condições naturais, as plântulas emergem em tempos diferentes e parte da progênie evita as condições climáticas mais desfavoráveis e uma herbivoria severa.
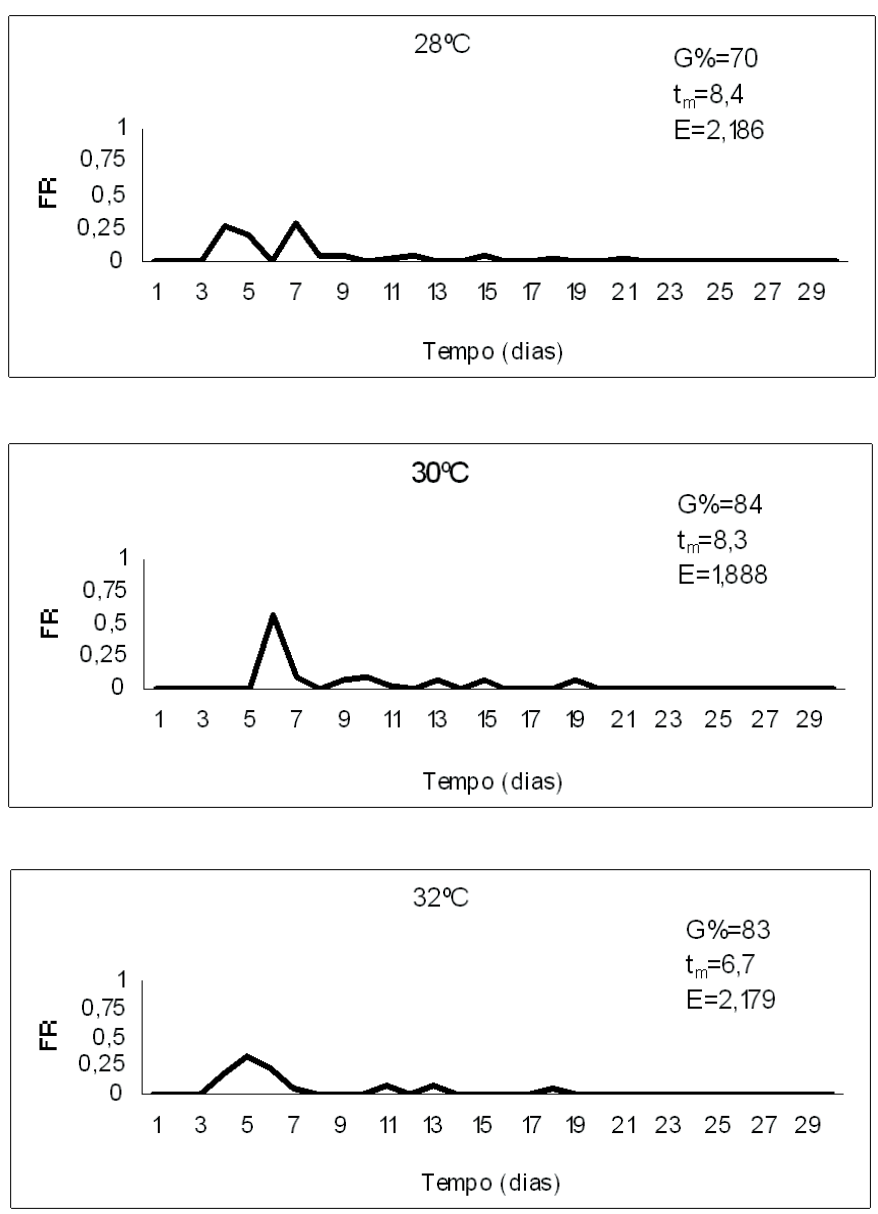

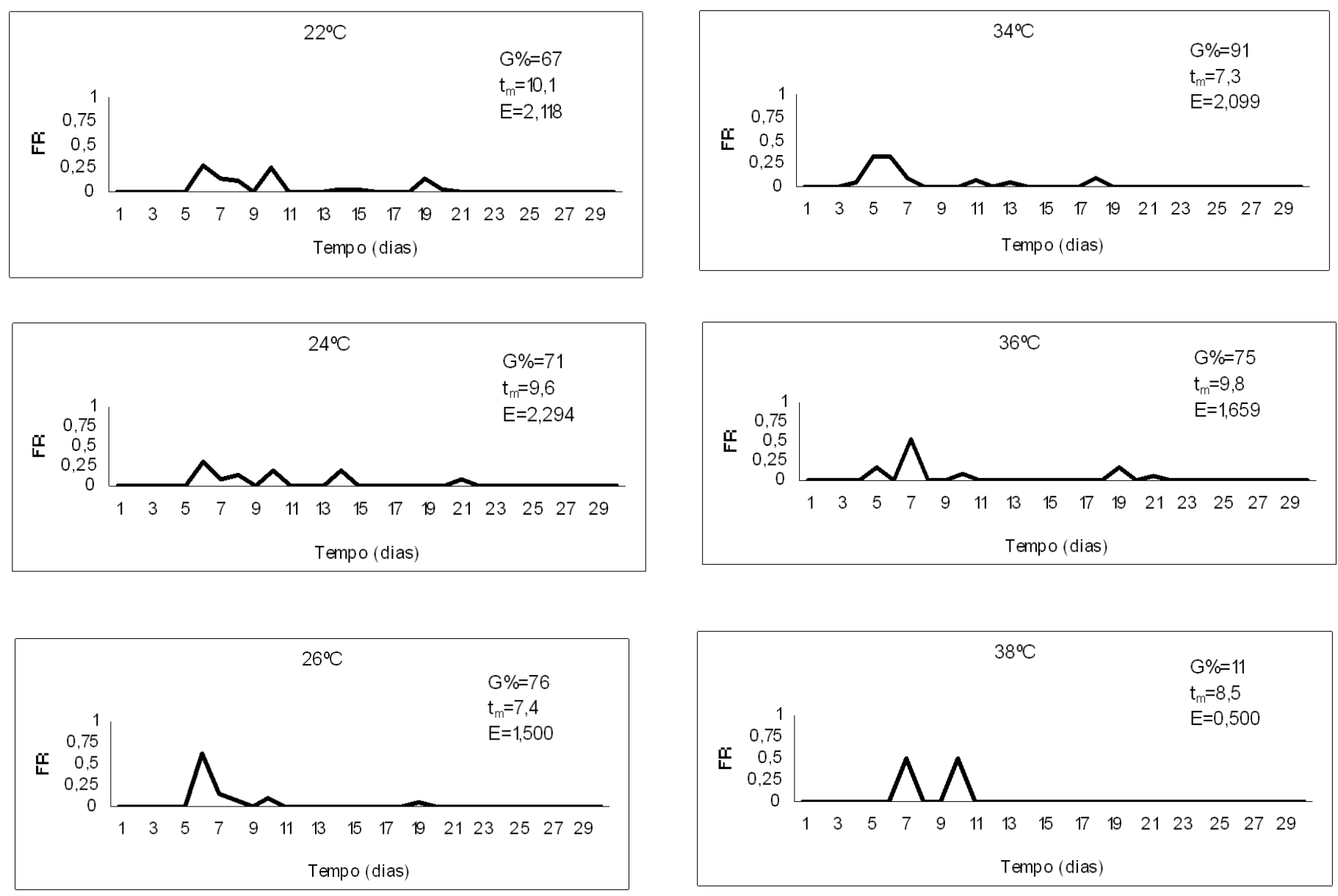

FIGURA 2. Distribuições de freqüência relativa (FR) da germinação de sementes de Erythrina variegata L. em função do período de incubação isotérmica. $G \%$ - porcentagem de germinação; $t_{m}$ - tempo médio de germinação (dias); E - índice de sincronização de germinação ou incerteza (bits).

Sob temperaturas mais baixas, $14^{\circ} \mathrm{C}$ a $20^{\circ} \mathrm{C}$, a germinação ocorreu mais tardiamente, podendose evidenciar que os picos de germinação surgiram próximos aos últimos dias de incubação (a partir do $15^{\circ}$ dia) (Figura 2). Germinação tardia sob temperaturas mais baixas foi similarmente observada em sementes de Senna macranthera (Cassaro-Silva, 2001), uma vez que a intensidade de respiração é maior quando se aumenta a temperatura, por isso, sob temperaturas mais baixas o processo de germinação é mais lento (Gutiérrez e Minelli, 1990). Além disso, Marcos Filho (2005) destaca que a redução gradativa da temperatura, em função dos efeitos sobre a velocidade de embebição e de mobilização de reservas, provoca decréscimo acentuado da velocidade de germinação. Conforme relatado por García e Di Stéfano (2000), sementes de Dalbergia retusa Hemsl. passam a evidenciar atraso na germinação abaixo de $25^{\circ} \mathrm{C}$.

$\mathrm{O}$ início da germinação ocorreu mais rápido quando as sementes foram mantidas sob temperaturas de $22^{\circ} \mathrm{C}$ e $24^{\circ} \mathrm{C}$, quando esta também passou a ser mais distribuída ao longo do tempo (Figura 2). Sob temperaturas mais elevadas a germinação ocorreu mais rapidamente, como verificada entre $26^{\circ} \mathrm{C}$ a $38^{\circ} \mathrm{C}$, onde os picos de germinação apareceram no início do tempo de incubação (a partir do terceiro dia, como observado em algumas dessas temperaturas). Essa antecipação da germinação foi também constatada por meio do tempo médio de germinação, uma vez que este foi menor nas temperaturas mais elevadas, como verificado a partir de $22^{\circ} \mathrm{C}$ (Tabela 1 e Figura 2). Sementes de Maquira sclerophylla (Ducke) C.C. Berg também apresentam redução no tempo de germinação com o aumento da temperatura (Miranda e Ferraz, 1999). 


\section{CONCLUSÕES}

Os limites de temperatura mínima e máxima para germinação de sementes de Erythrina variegata L. são $14^{\circ} \mathrm{C}$ e $38^{\circ} \mathrm{C}$, respectivamente;

A temperatura ótima para germinação de sementes de $E$. variegata é de $34^{\circ} \mathrm{C}$.

\section{AGRADECIMENTOS}

Os autores agradecem a CAPES pela concessão de bolsa ao primeiro autor e à Engenheira Agrônoma Marilda Torres Capucho pela ajuda na condução do trabalho.

\section{REFERÊNCIAS}

ABDO, M.T.V.N.; PAULA, R.C. Temperaturas para a germinação de sementes de capixingui (Croton floribundus Spreng. - Euphorbiaceae). Revista Brasileira de Sementes, v.28, n.3, p.135-140, 2006.

BEWLEY, J.D.; BLACK, M. Seeds: physiology of development and germination. 2. ed. New York and London: Plenum Press, 1994. 445p.

BORGES, E.E.L.; RENA, A.B. Germinação de sementes. In: AGUIAR, I.B.; PIÑA-RODRIGUES, F.C.M.; FIGLIOLIA, M.B. (Coord.). Sementes florestais tropicais. Brasília, DF: ABRATES, 1993. p.83-135.

BRADBEER, J.W. Seed dormancy and germination. New York: Chapman and Hall, 1988. 146p. (Tertiary Level Biology).

BRASIL. Ministério da Agricultura e Reforma Agrária. Secretaria Nacional de Defesa Agropecuária. Departamento Nacional de Produção Vegetal. Coordenação de Laboratório Vegetal. Regras para Análise de Sementes. Brasília, DF, $1992.365 \mathrm{p}$.

CARVALHO, N.M.; NAKAGAWA, J. Sementes: ciência, tecnologia e produção. 4. ed. Jaboticabal: FUNEP, 2000. $588 \mathrm{p}$.

CASSARO SILVA, M. Efeito da temperatura na germinação de sementes de manduirana (Senna macranthera (Collad.) Irwin et Barn. - Caesalpiniaceae). Revista Brasileira de Sementes, v.23, n.1, p.92-99, 2001.

CAVALCANTE, A.M.B.; PEREZ, S.C.J.G.A. Efeitos da temperatura sobre a germinação de sementes de Leucaena leucocephala (Lam.) de Wit. Revista Brasileira de Sementes, v. 17, n.1, p.1-8, 1995.
CROCKER, W.; BARTON, L.V. Physiology of seeds: an introduction to the experimental study of seed and germination problems. Waltham: Chronica Botanica Company, 1957. 267p. (A new series of plant science books, 29).

FARIA, S.M.; FRANCO, A.A.; CAMPELLO, E.F.C.; SILVA, E.M.R. Recuperação de solos degradados com leguminosas noduladas e micorrizadas. Seropédica: Embrapa Agrobiologia, 1998. 23p. (Embrapa. Documentos, 77).

GARCÍA, E.G.; DI STÉFANO, J.F. Temperatura y germinación de las semillas de Dalbergia retusa (Papilionaceae), árbol en peligro de extinción. Revista de Biología Tropical, v.48, n.1, p.43-45, 2000.

GODOI, S.; TAKAKI, M. Efeito da temperatura e a participação do fitocromo no controle da germinação de sementes de embaúba. Revista Brasileira de Sementes, v.27, n.2, p. 87-90, 2005.

GUTIÉRREZ, O.J.G.; MINELLI, M. La produccion de semillas. Managua: Imprenta Uca, 1990. 210p.

HEGDE, N.G. Cultivation and uses of Erythrina variegata in western India. In: WESTLEY, S.B.; POWELL, M.H. Erythrina in the new and old worlds. Paia: Nitrogen Fixing Tree Association, 1993. p.77-84.

HEGDE, N.G.; DALLA ROSA, K. Erythrina variegata: more than a pretty tree. Morrilton: FACT Net, 1994. (NFT Highlights, 94-02). Disponível em: <http://food-security. info/food-security.info/Winrock\%20Archive/e_variegata. html>. Acesso em: 13 abr. 2007.

KASS, D.L. Erythrina species: pantropical multipurpose tree legumes. In: GUTTERIDGE, R. C.; SHELTON, H.M. Forage tree legumes in tropical agriculture. Queensland: CAB International, 1994. p.84-96.

LABOURIAU, L.G. Germinação das sementes. Washington: Secretaria-Geral da Organização dos Estados Americanos, 1983. 174p.

LABOURIAU, L.G. Seed germination as a thermobiological problem. Radiation and Environmental Biophysics, v.15, n.4, p.345-366, 1978.

LABOURIAU, L.G.; PACHECO, A.A. Isothermal germination rates in seeds of Dolichos biflorus L. Boletín de la Sociedad Venezolana de Ciencias Naturales, v.34, p.73-112, 1979.

LABOURIAU, L.G.; VALADARES, M.E.B. On the germination of seeds of Calotropis procera (Ait.) Ait.f. Anais da Academia Brasileira de Ciências, v.48, n.2, p. 263-284, 1976. 
LARCHER, W. Ecofisiologia vegetal. São Carlos: Rima, 2000. 531p.

LOPES, J.C.; PEREIRA, M.D.; MARTINS FILHO, S. Germinação de sementes de calabura (Muntingia calabura L.). Revista Brasileira de Sementes, v.24, n.1, p.59-66, 2002.

LOPES, J.C.; SOARES, A. Germinação de sementes de Miconia cinnamomifolia (Dc.) Naud. Brasil Florestal, v.21, n. 75, p.31-38, 2003.

LORENZI, H.; SOUZA, H.M.; TORRES, M.A.V.; BACHER, L.B. Árvores exóticas no Brasil: madeireiras, ornamentais e aromáticas. Nova Odessa: Plantarum, 2003. $368 p$.

MARCOS FILHO, J. Fisiologia de sementes de plantas cultivadas. Piracicaba: FEALQ, 2005. 495p.

MATOS, L.V.; CAMPELLO, E.F.C.; RESENDE, A.S.; PEREIRA, J.A.R.; FRANCO, A.A. Plantio de leguminosas arbóreas para produção de moirões vivos e construção de cercas ecológicas. Seropédica: Embrapa Agrobiologia, 2005. (Sistemas de Produção: versão eletrônica, 3). Disponível em: <http://www.cnpab.embrapa.br/publicacoes/ sistemasdeproducao/moirao/outras.htm>. Acesso em: 6 abr. 2006.

MAYER, A.M.; POLJAKOFF-MAYBER, A. The germination of seeds. London: Pergamon Press, 1989. 270 p.
MIRANDA, P.R.M.; FERRAZ, I.D.K. Efeito da temperatura na germinação de sementes e morfologia da plântula de Maquira sclerophylla (Ducke) C.C. Berg. Revista Brasileira de Botânica, v.22, n.2, p.303-307, 1999. Suplemento

PEREZ, S.C.J.G.A.; FANTI, S.C.; CASALI, C.A. Limites de temperatura e estresse térmico na germinação de sementes de Peltophorum dubium (Spreng) Taubert. Revista Brasileira de Sementes, v.20, n.1, p.134-142, 1998.

POPINIGIS, F. Fisiologia da semente. Brasília, DF: AGIPLAN, 1985. 289p.

SANTANA, D.G.; RANAL, M.A. Análise da germinação: um enfoque estatístico. Brasília, DF: UnB, 2004. 248p.

VARELA, V.P.; RAMOS, M.B.P.; MELO, M.F.F. Umedecimento do substrato e temperatura na germinação de sementes de angelim-pedra (Dinizia excelsa Ducke). Revista Brasileira de Sementes, v.27, n.2, p.130-135, 2005.

WHISTLER, W.A.; ELEVITCH, C.R. Erythrina variegata (coral tree). In: ELEVITCH, C.R. Traditional trees of pacific islands: their culture, environment, and use. Holualoa: Permanent Agriculture Resources, 2006. p.329-344.

WILKINSON, K.M.; ELEVITCH, C.R. Propagation protocol for vegetative production of container Erythrina variegata L. "Tropic Coral' or 'Tall Erythrina" plants. Native Plant Network, Moscow, 2004. Disponível em: <http://www. nativeplantnetwork.org>. Acesso em: 21 jan. 2007. 